\title{
A CONSTRUÇÃO DA IDENTIDADE DISCURSIVA DOS IDOSOS DA UNATI: UNIVERSIDADE ABERTA DA TERCEIRA IDADE - UERJ
}

\section{Simone Vieira Resende \\ Doutoranda em Linguística Aplicada e Estudos da Linguagem pela Pontifícia Universidade Católica de São Paulo (PUC-SP) simonevi@corpuslg.org}

\section{RESUMO}

A construção de identidades no contexto de estudos sobre o envelhecimento tem sido foco de alguns estudos contemporâneos (Cf. GONÇALVES, 1999 \& SOUSA, 2006). Tais pesquisas destacam a importância do levantamento do perfil do idoso como elemento primordial para o desenvolvimento de políticas públicas direcionadas para essa parte da população. Entretanto, como esses estudos são generalizados e na sua grande maioria de cunho quantitativo, as identidades projetadas discursivamente nos depoimentos e falas dos idosos não aparecem como objeto de estudo. Este artigo corrobora para o preenchimento dessa lacuna, investigando como idosos, alunos do projeto Universidade Aberta da Terceira Idade (UnATI) no âmbito da Universidade do Estado do Rio de Janeiro constroem discursivamente suas identidades como frequentadores das oficinas e serviços oferecidos. A investigação é realizada com base nos estudos sociocognitivos e busca nas colocações lexicais informações para identificar os Modelos Cognitivos Idealizados (LAKOFF, 1987) projetados pelos idosos. Os dados foram obtidos por meio da extração das falas e depoimentos incluídos na publicação de comemoração dos 15 anos de fundação da UnATI e analisados qualitativamente a partir dos estudos sobre os processos identitários no discurso (SCHIFFRIN, 2006; ROGERS, 2004) e dos MCIs. Os resultados sinalizam que, discursivamente, as identidades projetadas pelos idosos que frequentam a UnATI consolidam-se nos modelos cognitivos e culturais construídos a respeito desse idoso e reafirmam o papel que a UnATI assume institucionalmente. O levantamento mapeia identidades projetadas pelos discursos analisados e procura homogeneizar este conceito para que a compreensão destas identidades discursivas influencie o desenvolvimento de novas oficinas e cursos que atendam essa parte da população.

Palavras-chave: identidades discursivas, MCls, idosos, UnATI, análise de discurso.

\begin{abstract}
The construction of identities within the context of studies that focus on processes of aging has been the object of some contemporary studies (Cf. GONÇALVES, 1999 \& SOUSA, 2006). Those researches underline the relevance of surveying the profile of the elderly as a key element for the development of public policies regarding the welfare of this population group. However, considering that such studies are mostly quantitative and concerned with establishing a general overview, the identities which are discursively projected in the testimonials and discourse of the elderly are not featured as objects of study. This article aims to fill this gap, investigating how senior citizens enrolled at Rio de Janeiro State University's Universidade Aberta da Terceira Idade (UnATI) project build their identities in a discursive manner as students who attend workshops and events offered there. My investigation is going to be developed using sociocognitive studies as a basis while looking for information in the students' lexical constructions to identify the Idealized Cognitive Models (LAKOFF, 1987) that are projected by them. The data published here was obtained by selecting testimonials included in a commemorative publication for the 15th anniversary of the foundation of UnATI. This data is going to be analysed under a qualitative paradigm and based on studies about ICMs and those focused on discourse and identity (SCHIFFRIN, 2006; ROGERS, 2004). The results found here suggest that, in a discursive manner, the identities which are projected by the elderly students enrolled at UnATI are cemented on the cognitive and cultural models built around the elderly in general, thus reaffirming the institutional role of UnATI. This survey maps out the identities which are projected by the discourse found in the testimonials analysed here and aims to homogenise this concept so that the understanding of these discursive identities can have an influence on the development of new workshops and courses to accommodate this sector of society.
\end{abstract}

Keywords: discursive Identities, ICMs, elders, UnATI, discourse analysis. 


\section{Introdução}

Pesquisas na área do envelhecimento (PRADO; SAYD, 2004), (VERAS; CALDAS, 2004), (VERAS, 2008), (GONÇALVES, 2008) apontam que o envelhecimento da população será um dos maiores problemas sociais a serem enfrentados em um futuro próximo em todo o mundo. É urgente que governos e universidades comecem a dar atenção a essa grave questão organizando centros ou institutos não apenas para os estudos biológicos do envelhecimento, mas também para os sociais. Para que isso aconteça, é preciso conhecer o perfil desse idoso.

Há alguns estudos sobre a identidade do idoso (Cf. GONÇALVES, 1999; SOUSA, 2006), que apesar de contribuírem para entendermos melhor a construção das muitas possíveis identidades dessa parte da população, são ainda muito tangenciais, principalmente no que diz respeito ao idoso que frequenta a UnATI (Universidade Aberta da Terceira Idade), projeto de extensão da Universidade do Estado do Rio de Janeiro (UERJ). Seria complicado assumirmos que há apenas uma identidade para este idoso, ou seja, um conceito homogêneo que englobasse toda a população.

Sendo assim, apesar de apresentarmos uma tentativa de descrição única dessa identidade é preciso elucidar que o discurso tende a projetar muitas identidades e que não seria adequado descartar a multiplicidade e a variedade. Uma estratégia eficaz para traçar o processo de construção dessas identidades é por meio da análise do discurso produzido pelos idosos.

O objetivo desse estudo é investigar a construção das identidades dos idosos, mais especificamente, os idosos alunos da UnATI. Inspirada pelos estudos sociocognitivos, esta pesquisa tenta buscar nas colocações lexicais as pistas para identificar os Modelos 
Cognitivos Idealizados (MCls) (LAKOFF, 1987) projetados discursivamente pelos idosos a partir de dados advindos de depoimentos e falas que aparecem na publicação "15 Anos na flor da maturidade - a Juventude de uma senhora universidade" (VERAS, 2008). MCls são modelos ativados cognitivo-culturalmente, por meio de percepções corpóreas advindas de valores ou crenças e que ajudam a organizar diversos domínios do conhecimento, fundamentais aos processos de comunicação.

A partir da análise dos dados pretende-se responder três perguntas: (1) Qual a identidade discursiva dos idosos projetada pelos depoimentos, falas e citações publicadas no corpus analisado? (2) Quais Modelos Cognitivos Idealizados dos idosos estão presentes nos corpora analisados? (3) Como os MCls podem ajudar na elaboração de objetivos, e metas que possam nortear a criação de novas oficinas e cursos, tanto para os idosos quanto para aqueles que trabalham diretamente com eles?

A primeira parte do estudo é uma revisão de literatura sobre os conceitos aplicados nesse estudo: os conceitos de identidade e a construção de identidades discursivas, destacando-se os estudos de Schiffrin (2006) e Rogers (2004) e o conceito de Modelos Cognitivos Idealizados de Lakoff (1987). A segunda etapa descreve o contexto da UnATI como campo de estudo, os participantes da pesquisa, o corpus utilizado, a metodologia adotada e os procedimentos da pesquisa. A terceira etapa apresenta a análise dos dados, os MCls ativados e como eles influenciam a construção de identidades discursivas. Esta terceira e última etapa traz também uma discussão e comparação entre a visão do idoso que não frequenta um programa de estudo em contraste com o idoso que frequenta as oficinas da UnATI.

\section{Revisão da literatura}


Este estudo pretende levantar as identidades discursivas dos idosos, protagonistas dos artigos publicados na revista de comemoração dos 15 anos de fundação da UnATI, intitulada: "15 anos na flor da maturidade - A Juventude de uma senhora universidade" (2008). Para tanto, utilizarei uma abordagem sociocognitivista baseada em dois conceitos: (i) as pistas linguísticas para investigar a rede lexical que constrói a identidade do idoso, enquanto um $\mathrm{MCl}$, ou seja, os Modelos Cognitivos Idealizados (LAKOFF, 1987), e (ii) o processo de construção de identidades (SCHIFFRIN, 2006; ROGERS, 2004), que por sua vez, também nos remetem as ideias de Goffman (1998) a respeito da construção de identidades. A ideia é que esses dois pontos se complementem a partir do princípio de que as identidades podem ser entendidas como um construto homogêneo, uma vez que os $\mathrm{MCls}$ emergem das pistas discursivas analisadas e assim estruturam a identidade social descrita no corpus.

Uma justificativa para a escolha desse conjunto teórico vem das ideias de Salomão (2006). A autora afirma que a linguagem existe para que as pessoas possam relatar a história de suas vidas, mentir sobre elas, expressar desejos e temores, tentar resolver problemas, avaliar situações, influenciar seus interlocutores, predizer o futuro, planejar ações. Quando se concebe a linguagem nestes termos, é possível observar as contribuições dos sinais linguísticos - de semioses como vocalização, expressão corporal e no caso deste estudo a evocação de $\mathrm{MCls}$ - para a construção do sentido. A investigação de questões desse tipo requer uma concepção da linguagem como artefato cultural capaz de mediar processos sociocognitivos em contextos situados de uso.

\section{Modelos Cognitivos Idealizados - MCls}


MCls são estruturas estáveis, de memória pessoal e social que organizam nosso conhecimento que, por sua vez, também é socialmente construído na e pela interação do homem com o outro e com o meio que o cerca, estando disponíveis em cada cultura (LAKOFF, 1987, p. 69). A capacidade que temos de utilizar e reutilizar o conhecimento que adquirimos por meio das experiências e das interações uns com os outros nos ajuda a entender e identificar tipos diferentes de práticas sociais. É exatamente essa perspectiva que vai corroborar o levantamento das identidades dos idosos que depõem nos artigos da publicação comemorativa da UnATI, pois são as pistas linguísticas que sinalizam o Modelo Cognitivo Idealizado - IDOSO - projetado no texto.

Nossa intenção neste estudo é de utilizar as pistas encontradas para evocar um ou mais $\mathrm{MCl}$ do idoso, ou seja, as múltiplas e variadas identidades sociais desse grupo que não é estático, mas que pode ser descrito de acordo com determinadas pistas interacionais que nos ajudam a conversar com os dados e não a impor conceitos teóricos a eles.

Essas pistas vão ativar os espaços mentais que nós construímos acerca da figura do idoso, nos ajudando a levantar a identidade desse indivíduo. Os espaços mentais são os universos hipotéticos da realidade, os quais a mente cria para organizar as categoriais de conhecimento e as estratégias da cognição. A elaboração, definição e exemplificação dos $\mathrm{MCls}$ são importantes para a estrutura desse estudo. É por meio deles que levantamos as diferentes identidades dos idosos que frequentam as oficinas e cursos da UnATI. Os MCls são as estruturas de expectativas que criamos a respeito de algo. Eles são as nossas antecipações e funcionam como um sistema de crenças ou de categorias. Os 
modelos culturais são um tipo de $\mathrm{MCl}$. É possível afirmar que o espaço mental do $\mathrm{MCl}$ é efêmero e o espaço cognitivo é estático. Observe os exemplos (1) e (2):

(1) Certa vez, já passando dos 70, foi procurar a UnATi, ele andava deprimido. Vinha sendo tratado com medicamentos.

(2) Ele é o futuro do Brasil, na hora do vestibular, tem que escolher que carreira vai seguir pro resto da vida.

Nestes dois casos, é inequívoco que o pronome em (1) se refira ao idoso e que, em (2), se refira ao jovem. O interessante nestes dois casos é que são os $\mathrm{MCl}$ s que promovem o contexto para o entendimento da mensagem. Em outras palavras, o contexto é promovido por Modelos Cognitivos Idealizados, dentro dos quais determinados papeis (roles), são suscitados por informação lexical específica, constituindo uma antecedência para a realização referencial dos pronomes.

\section{Os processos identitários}

Goffman (1985) que diz que o sujeito social é constituído por marcas pessoais e sociais, história, classe social e relações interpessoais. Aplicações dessas ideias podem ser encontradas em dois estudos a respeito dos processos de construção de identidade. 0 primeiro é de Deborah Schiffrin (2006), o segundo, de Rebecca Rogers (2004). As duas autoras destacam o quanto as referências linguísticas podem apresentar pistas sobre as identidades daqueles que nem fazem parte diretamente do discurso. 
O objetivo do trabalho de Deborah Schiffrin (2006) é entender como os termos referenciais (referências linguísticas) projetam identidades no mundo textual dos personagens sobre os quais falamos (incluindo, mas não se limitando, ao gênero das narrativas e relatos de vida) e também, no mundo social das pessoas com quem interagimos, já que esses dois mundos estão interligados.

Primeiramente, ela discorre sobre a importância dos substantivos (locuções substantivas) para o entendimento da fala. A autora chama essas locuções substantivas de referências linguísticas. Ela não as considera apenas pronomes ou pessoas, mas sim, personagens que têm características específicas e que formam relações sociais que emergem de um mundo social concreto. O trabalho descrito mostra como algumas das pistas identitárias podem aparecer principalmente nas narrativas e nas histórias de vida, assim como, nas escolhas lexicais, no uso de substantivos e de pronomes, nos padrões sequências de referências a terceira pessoa e como tudo isso pode revelar facetas diferentes das identidades dos falantes.

As duas autoras baseiam suas pesquisas nas ideias de Ervin Goffman (1985). Ele elaborou uma explicação social, sociogênica do self, do eu. Em outras palavras, a proposta de Goffman (1985), para unir sociedade e self em uma única estrutura conceitual foi fazer uma explicação sociogênica do self. Goffman (1985) desenvolveu uma concepção do self como uma construção social. Essa concepção ajudou a unir a divisão teórica e analítica entre o self e a sociedade através da reconceituação de como o "outro" e a sociedade estão relacionados entre si e de como os dois estão relacionados ao self. Em suma, "o outro" é uma representação microcósmica da sociedade; o outro/sociedade e o self são interdependentes porque as necessidades de cada um são atendidas pelas do outro. 0 
mais importante é entender que a interação entre os três é construída com semelhanças e diferenças.

Schiffrin (2006) complementa suas ideias a respeito da construção de identidades discorrendo sobre referência e identidade em uma entrevista sociolinguística. Nesse estudo, a técnica da entrevista não foi utilizada, porém a intenção é basicamente a mesma, apesar de não haver uma pergunta explícita, apenas uma resposta, um comentário, uma fala ou um depoimento a respeito das experiências vividas pelas pessoas participativas da UnATI. Mesmo não havendo uma entrevista com os participantes, as seleções das falas e dos depoimentos também estão focadas nas descobertas das múltiplas e variadas identidades. Nas entrevistas, assim como na análise das falas selecionadas para esta pesquisa, o objetivo é identificar as identidades de uma classe, de um grupo de pessoas, neste caso, os idosos.

Schiffrin (2006) oferece o exemplo de uma linguista entrevistando outra pessoa em diferentes locais para que possa ter reações diferentes e emitir opiniões diferentes, seja por vontade própria ou pelo estímulo da entrevistadora. O foco de análise é a autorreparação inicial e autorreparação final dos termos referenciais. Tal referência não tem ligação externa direta com o falante ou com o ouvinte, ela tem papeis múltiplos na interação social. A referência é o objeto da reparação inicial e terminal, sendo preciso juntar essas referências para construir as identidades.

Uma única referência que dá informação a respeito de uma entidade no mundo textual contribui para a formação de atos discursivos complexos que transmitem informações a respeito de quem está falando com quem no mundo social. A autora propõe um modelo de análise de discurso no qual os domínios diferentes e as relações entre eles fornecem um sistema onde esses marcadores funcionam. Segundo a autora, há 
uma estrutura ideacional (Ideational Structure) que se refere ao lugar onde está o falante, o ouvinte e o conhecimento de cada um, assim como o meta-conhecimento. Há ainda, o lado social do falante e do ouvinte, o alinhamento, a relação entre eles e o que eles estão dizendo.

Schiffrin também afirma que há uma estrutura de ação (Action Structure), que se refere ao conhecimento estruturado, o que realmente é importante, o que realmente conta, o que está acontecendo. E por último, uma estrutura de troca (Exchange Structure), que se refere ao direito de falar e de ouvir e a troca de papéis.

Para finalizar, pode-se afirmar que, aqueles sobre quem falamos e o que dizemos sobre eles, tornam-se parte do nosso mundo social. Uma referência serve não somente para entender o significado de uma locução, mas sinaliza como o significado no contexto daquela elocução contribui para os mundos sociais nos quais construímos nossas identidades.

\section{Metodologia}

Com o advento do Estatuto do Idoso em 2003 (BRASIL, 2003), idosos e discussões sobre envelhecimento passaram a ocupar espaço maior na mídia e nas pesquisas acadêmicas. Os modelos e padrões relacionados ao processo de envelhecimento e principalmente a figura e identidade do idoso são frequentemente relacionados a aspectos negativos: “O idoso está num determinado patamar. Quando cai, não volta mais ao patamar anterior. Vai em queda, degrau por degrau." (VERAS, 2008). Tal afirmação pode refletir uma realidade. Contudo, projetos como a UnATI possibilitam que pessoas idosas rompam com esta imagem consolidada pelo senso comum. A proposta da UnATI é 
“manter esse degrau o mais longo possível. A queda virá, mas a gente tenta fazer com que ela seja mais curta" (VERAS, 2008).

Com a finalidade de examinar as pistas linguísticas que constroem as redes que projetam as identidades dos idosos que frequentam a UnATI na UERJ, utilizamos o arcabouço da Análise do Discurso sob a ótica sociocognitiva, lançando mão de conceitos como MCls (Modelos Cognitivos Idealizados) e seus scripts, cenários e espaços mentais (LAKOFF, 1987; MARCHUSCHI, 2001; STUBBS, 2001; FLOWERDEW, 2002; SOARES, 2006). O estudo utiliza também os princípios que norteiam a construção de identidades e as pesquisas a respeito de discurso e identidade feitas por nomes como Rogers (2004), Schiffrin (2006), Saliés (2004) e outros.

O corpus escolhido para a realização da pesquisa foi a revista publicada pela UnATi em comemoração aos seus 15 anos de fundação "15 anos na flor da maturidade" (VERAS, 2008). A princípio, foram selecionadas as falas, depoimentos, relatos e narrações dos idosos a respeito das experiências vividas durante o seu período como alunos da UnATI. Ao todo foram selecionadas cinco falas proferidas pelos idosos.

Como vimos, o objetivo é investigar, por meio dos $\mathrm{MCls}$, as diversas identidades discursivas dos idosos projetadas em suas falas e narrações. Observar, analisar e registrar como os $\mathrm{MCls}$ podem ajudar a delinear as identidades desses idosos, uma vez que são partes e contrapartes dos espaços mentais que investigamos e a partir daí entender como eles podem ajudar na elaboração de objetivos, metas que possam nortear a criação de novas oficinas e cursos.

As perguntas que orientam esta pesquisa são: Quais são as identidades discursivas dos idosos projetadas pelos depoimentos, falas e citações publicadas no corpus analisado? Quais Modelos Cognitivos Idealizados dos idosos estão presentes nos corpora 
analisados? Como os MCls podem ajudar na elaboração de objetivos, metas que possam nortear a criação de novas oficinas e cursos, tanto para os idosos quanto para aqueles que trabalham diretamente com eles?

Para responder a essas perguntas, o estudo lança mão da investigação das falas e dos depoimentos retirados da publicação e analisa as colocações lexicais, que servem como pistas linguísticas formando redes que constroem as identidades. A análise é feita por meio do destaque das referências que emergem das falas, ou seja, as figuras e ideias sobre as identidades no mundo textual e no social.

A metodologia utilizada baseia-se no modelo de Schiffrin (2006) para encontrar as relações entre as pistas linguísticas e então construir as diversas identidades. Por último, a pesquisa apresenta a construção de $\mathrm{MCl}$ dos idosos com o intuito de elaborar um modelo geral que possa representar o entendimento do grupo sobre as múltiplas identidades dos idosos que frequentam a UnATI.

\section{Análise}

\subsection{A rede lexical que constrói as identidades dos idosos da UnATI}

Como o propósito deste estudo é levantar as diversas identidades discursivas dos idosos da UnATI, o artigo investiga a rede lexical que constrói essas identidades, tendo como base os Modelos Cognitivos Idealizados e os processos identitários já apresentados na revisão da literatura.

Nossa habilidade humana de dominar, retomar e utilizar os conceitos contraídos pela experiência nas interações com o mundo e com os outros é o que torna possível a 
compreensão de diferentes tipos de contextos. Nessa situação, analisamos as pistas linguísticas que sinalizam os $\mathrm{MCls}$ de forma mais generalizada em discursos a respeito dos idosos, como por exemplo, O Estatuto do Idoso (BRASIL, 2003), as pesquisas do IBGE e as pesquisas da OMS.

Na realidade, as ideias que temos acerca da figura do idoso e o que lemos a respeito dele atuam como um ativador de espaços mentais, isto é, universos hipotéticos da realidade que nossa mente cria para organizar categorias de conhecimento e estratégias da cognição são estruturados, dentre outros, por $\mathrm{MCl}$. Quando pedimos a uma pessoa que descreva um idoso, ou que fale de uma pessoa idosa, ou até mesmo quando lemos a definição de idoso no dicionário, estamos ativando espaços mentais e os MCls, uma vez que eles são ativados para estruturar os espaços mentais que flutuam ou fluem no discurso. Os MCls já estão na nossa memória de longo prazo e podem influenciar nosso modo de perceber um determinado indivíduo, situação ou texto.

Não podemos nos esquecer da nossa própria experiência como viventes dessa situação, já que envelhecemos a cada dia. Para ilustrar a relação da linguagem como pista para a construção das muitas identidades do idoso no Brasil, buscamos citar alguns estudos que relatam como o idoso é visto em um contexto geral, em seguida elaborando o $\mathrm{MCl}$ projetado por essas visões. Vale ressaltar que é tanto a partir do discurso quanto a partir da visão da cultura e da sociedade que as ideias e conclusões são construídas aqui. Estas últimas formam outro tipo de $\mathrm{MCl}$ entendido como Modelo Cultural complementar para as análises feitas neste estudo.

Para conhecer a condição do idoso no Brasil hoje, temos acesso a dados quantitativos, como raça, cor, idade, situação financeira, moradia, entre outros recolhidos pelo IBGE e pela OMS. No entanto, os estudos relacionados aos idosos e ao 
envelhecimento não podem ficar somente no campo da análise quantitativa, sendo preciso complementar a pesquisa com questões qualitativas.

A OMS (2008) prevê que por volta de 2025, pela primeira vez na história, teremos mais idosos do que crianças no planeta. De acordo com o IBGE (2006), o Brasil será o sexto país com o maior número de pessoas idosas. Surge assim a necessidade de serem criadas políticas sociais que preparem a sociedade para essa realidade. Veras (2008) descreve ricamente a população idosa brasileira. Contudo, apesar do crescimento dos estudos sobre o idoso, a velhice e o processo de envelhecimento (Cf. PRADO \& SAYD, 2004), os estudos que descrevem os idosos são predominantemente quantitativos. 0 estudo "Envelhecimento Ativo" publicado pela OMS declara:

Pessoas idosas apresentam maior probabilidade de perderem membros e amigos da família, de serem mais vulneráveis à solidão, isolamento social e de terem a disponibilidade de um 'menor grupo social'. Isolamento social e solidão na velhice estão ligados a um declínio de saúde tanto física como mental. Em muitas sociedades, homens têm menos chance do que as mulheres de obterem redes de apoio social. Entretanto, em algumas culturas, mulheres idosas que ficam viúvas são sistematicamente excluídas da sociedade ou até rejeitadas pelas suas comunidades. (...) A proporção de homens e mulheres na população de 60 anos ou mais reflete a maior proporção de mulheres que homens em todas as regiões do mundo, especialmente nas regiões mais desenvolvidas (OMS, 1989).

O Estudo da Organização Mundial da Saúde, portanto, apresenta os idosos como solitários (grifo nosso) e as mulheres viúvas como excluídas e rejeitadas pela sociedade. Sousa (2008) menciona em seu artigo que a chamada "terceira idade" é uma construção recente que se refere àquela pessoa entre a idade adulta e a velhice, enxergado sob o estigma da marginalização e da solidão. Outro aspecto interessante concerne a palavra "velho", que passou a ser considerada politicamente incorreta, por estar associada à ideia 
de coisa inútil ou imprestável, ressaltando ainda as ações governamentais em prol da mudança de nomenclatura. No Brasil, as instituições públicas passaram a adotar outra representação das pessoas envelhecidas, banindo o termo em questão dos textos oficiais. O termo "idoso" foi amplamente adotado.

Gonçalves (2008), por sua vez, não trabalha o aspecto do idoso como ator político, mesmo porque sua pesquisa não se dá no contexto dos estudos do Direito. Por outro lado, ela constrói uma identidade social a partir de estereótipos acerca de pessoas idosas:

\begin{abstract}
Umas das principais constatações quanto à pessoa idosa é a posição negativa ocupada na sociedade atual e as consequências na sua rotina diária, ou seja, implicações em cada um dos componentes: social, físico, psicológico e cognitivo. Esta negatividade atribuída ao idoso é consequência da compreensão do envelhecimento, isto é, entende-se que envelhecer é algo ruim pela sua associação ao desgaste, degeneração, diminuição, entre outros. O envelhecimento não é doença, porém, através de exemplos simples da vida cotidiana, percebese que modela a pessoa idosa como um ser doente e frágil. Problemas psicológicos podem ser desenvolvidos pela constante e massificada afirmação de declínios que devem ocorrer nas funções gerais do organismo e nas mudanças exteriores no corpo (GONÇALVES, 2008, grifo nosso).
\end{abstract}

Gonçalves também enfatiza o fato de que o idoso é visto socialmente como um ser carente e marginalizado, seja pela sua modificação física, seja pela ausência de papel produtivo, fator inerente ao sistema capitalista. Segundo Sherman e Gold (1979), existe um estereótipo negativo para com os idosos, que inclui características como: visão de doença, de cansaço, de ausência de interesse sexual, de mentalidade lenta, de esquecimento, de menor habilidade para novas aprendizagens, de menor probabilidade de participar em atividades, de ser resmungão, retraído, isolado, improdutivo, defensivo, entre outras (McTAVISH apud SHERMAN; GOLD, 1979). A partir das informações dessas 
duas publicações - as referências e as pistas linguísticas - é possível construir um $\mathrm{MCl}$ do idoso baseado numa visão global, generalizada, categorizada e baseada nas expectativas, experiências e lembranças que temos sobre os idosos.

O quadro a seguir (Quadro 1) apresenta o $\mathrm{MCl} 1$ ativado a partir da análise do Estatuto do Idoso, das informações da OMS e dos dados do IBGE. O quadro ilustra a relação entre a prática social (o preconceito contra os idosos), a linguagem como pista (o negativismo da figura do idoso refletido na linguagem) e o pensamento (envelhecer é exatamente isso para a maioria das pessoas).

Quadro 1 - $\mathrm{MCl} 1$ - Os idosos pela sociedade

\begin{tabular}{|c|c|}
\hline$\checkmark$ imprestável & $\checkmark$ marginalização \\
\hline$\checkmark$ ator político & $\checkmark$ solidão \\
\hline$\checkmark$ velho inútil & $\checkmark$ decadência \\
\hline$\checkmark$ ruim & $\checkmark$ degeneração \\
\hline$\checkmark$ doente & $\checkmark$ diminuição \\
\hline$\checkmark$ frágil & $\checkmark$ desgaste \\
\hline$\checkmark$ carente & $\checkmark$ declínios \\
\hline$\checkmark$ resmungão & $\checkmark$ mudanças exteriores no corpo \\
\hline$\checkmark$ retraído & $\checkmark$ doença \\
\hline$\checkmark$ isolado & $\checkmark$ esquecimento \\
\hline$\checkmark$ improdutivo & $\checkmark$ cansaço \\
\hline$\checkmark$ defensivo & $\checkmark$ menor habilidade para novas \\
\hline$\checkmark$ rejeitadas & aprendizagens \\
\hline \multirow[t]{5}{*}{$\checkmark$ viúva } & $\checkmark$ ausência de interesse sexual \\
\hline & $\checkmark$ mentalidade lenta \\
\hline & $\checkmark$ isolamento social \\
\hline & $\checkmark$ problemas psicológicos \\
\hline & $\checkmark$ mulheres \\
\hline
\end{tabular}

As pistas relacionadas Quadro 1 permitiram a elaboração do $\mathrm{MCl}$ projetado discursivamente pelas pesquisadoras que redigiram os dois textos sobre a identidade do 
idoso (GONÇALVES, 2008; SOUSA, 2008), pelas informações da OMS, do IBGE e do Estatuto do Idoso (grifadas no texto). O modelo reflete não apenas as descobertas e descrições das pesquisadoras, mas também as categorias daqueles estudados por elas quando da construção de seus corpora. O mesmo acontece com as informações retiradas das outras três fontes. Este $\mathrm{MCl}$ revela um conjunto de experiências caracterizadas apenas por expressões negativas. A rede lexical destaca palavras que apesar de não terem em si uma carga negativa, neste contexto podem agir de forma diferente; por exemplo, os termos "viúvas" e "mulheres" evocam uma imagem que remete a solidão e fragilidade. Da mesma forma, acredita-se que o conjunto das vivências dos idosos da UnATI possa ser revelado e sinalizado, por meio das pistas projetadas no discurso, nos depoimentos, nas opiniões e nas falas apresentadas. Um aspecto relevante para este estudo encontra-se no fato de que apesar dos aspectos negativos listados acima, Gonçalves (1999) defende que a maioria dos idosos não se define deste modo.

Com base nos depoimentos coletados da publicação de comemoração dos 15 anos de fundação da UnATI, este estudo busca entender as identidades discursivas dos idosos que frequentam os cursos e oficinas da UnATI que emergem por meio das pistas linguísticas presentes em suas falas. A partir da análise das colocações lexicais das falas dos idosos, a pesquisa desenha diferentes $\mathrm{MCls}$ (um para cada depoimento) e posteriormente busca construir com uma interpretação conjunta para agrupar as identidades identificadas em um único $\mathrm{MCl}$ dos idosos. A investigação feita aqui busca perpassar os quatro princípios que operam os MCls revisitando os (1) Espaços mentais; (2) as Molduras comunicativas; (3) os Esquemas Imagéticos e (4) as Projeções metafóricas e metonímicas. Além disso, buscamos ainda as referências linguísticas que evoquem as identidades daqueles que falam e também daqueles sobre quem se fala com base no 
modelo elaborado por Schiffrin (2006). O Quadro 2 apresenta os $\mathrm{MCls}$ ativados a partir da análise da publicação "Quinze anos na flor da maturidade".

Quadro 2- $\mathrm{MCl} 2-\mathrm{O}$ Idoso pelo Idoso

\begin{tabular}{|c|c|c|}
\hline IDOSOS & ANTES DA UnATI & DEPOIS DA UnATI \\
\hline IARACY (1) & $\begin{array}{l}\text { * a viuvez } \\
\text { * depressão }\end{array}$ & $\begin{array}{l}\text { * cursos } \\
\text { * modelo } \\
\text { * bem de saúde } \\
\text { * de paz } \\
\text { * de amor } \\
\text { * amigos } \\
\text { * feliz }\end{array}$ \\
\hline $\begin{array}{l}\text { ANGÉLICA e OUTRAS } \\
\text { IDOSAS DA UnATI (2) }\end{array}$ & $\begin{array}{l}* \text { perdem o marido } \\
* \text { cabecinha baixa } \\
* \text { não querem fazer as } \\
\text { atividades } \\
* \text { uma carinha feia }\end{array}$ & $\begin{array}{l}\text { * aí eu converso } \\
* \text { curso } \\
* \text { namorada } \\
* \text { esposa } \\
* \text { mudança radical } \\
* \text { casaram } \\
* \text { namorar } \\
* \text { representante }\end{array}$ \\
\hline MARIA DE LOURDES (3) & $\begin{array}{l}\text { * doente } \\
* \text { ele: Dr. Paulo Henrique } \\
* \text { remédios } \\
* \text { médico } \\
* \text { idoso } \\
* \text { tristeza } \\
* \text { doença }\end{array}$ & $\begin{array}{l}\text { * sorriu } \\
\text { * esquecer "-istas" } \\
\text { * riso e alegria } \\
\text { * esquece doenças } \\
\text { * e não sentir solidão } \\
\text { * cursos } \\
\text { * oficinas } \\
\text { * aluna da UnATI desde o } \\
\text { dia da fundação } \\
\text { * melhores recordações }\end{array}$ \\
\hline HÉLIO (4) & & $\begin{array}{l}* \text { novas amizades } \\
* \text { aposentado } \\
* \text { convivência } \\
* \text { relacionar com pessoas } \\
* \text { dança de salão }\end{array}$ \\
\hline ABIESILDA (5) & * era jovem & $\begin{array}{l}\text { * uma outra pessoa } \\
\text { * estuda francês }\end{array}$ \\
\hline
\end{tabular}




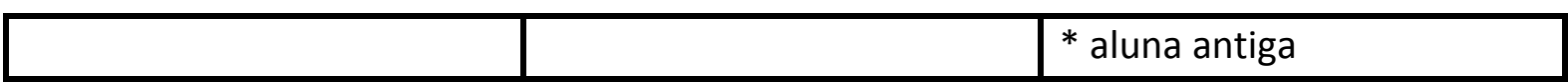

Os alunos da UnATI organizam suas produções textuais (neste caso, os depoimentos, as falas e as narrativas registradas no Quadro 2 a partir dos $\mathrm{MCls}$ disponíveis em suas memórias de longo prazo construídos a partir de suas próprias experiências. Tais estruturas de conhecimento são produzidas culturalmente e se estabelecem de acordo com os costumes locais e com as experiências e vivências de cada indivíduo.

É possível notar no Quadro 2 que os MCls são estáveis, mas não estáticos. Eles se modificam à medida que a pessoa passa por novas experiências. Isso explica a divisão entre o "antes" e o "depois" de frequentar a UnATI. A segunda coluna, que registra a rede lexical "antes da UnATI" está intimamente relacionada à visão consolidada do idoso pela sociedade, descrita no Quadro 1. Ambas constroem a identidade do idoso em uma base negativa.

É evidente a mudança na construção da identidade do idoso quando o discurso é proferido por ele mesmo: "Vou fazer 77 anos, estou bem de saúde, de paz e de amor. Tenho um filho maravilhoso, três netos maravilhosos e grandes amigos. Sou uma pessoa feliz. Neste contexto, laracy constrói uma imagem do idoso que soa positiva. Também é possível identificar como os termos referenciais usados por ela fornecem pontes para os diferentes mundos sociais onde a identidade é construída. Isto é, o efeito positivo da experiência na UnATI tem reflexos em sua vida pessoal. É provável que essas conclusões se repitam nos próximos contextos analisados. Mesmo que alguns dos participantes não revelem conscientemente informações sobre suas vidas antes da experiência da UnATI, é possível perceber essas mensagens por meio das pistas que aparecem em seus discursos. 
Angélica (participante 2), por exemplo, quando se refere às idosas que chegam à UnATI e descreve como elas chegam e como elas se tornam, parece utilizar como parâmetro sua própria experiência quando iniciante no projeto. A base para a ativação do $\mathrm{MCl}$ são as pistas linguísticas que aparecem no seu discurso, já que há projeções não apenas a respeito da pessoa que fala, como também sobre quem ela fala: "tem idosas que perdem o marido", "chega de cabecinha baixa". Essas características nos remetem ao $\mathrm{MCl}$ evocado no Quadro 1. Alguns termos como "viúva" e "triste" surgem nos dois MCls e fortalecem a imagem negativa consolidadas acerca de idosos de forma geral (Quadro 1) e dos idosos que não frequentam a UnATI (Quadro 2, coluna 1). A expressão usada por Angélica "aí eu converso" é uma referência que revela muito sobre sua própria identidade enquanto divulgadora do projeto, convidando outros idosos para a universidade por meio do testemunho sobre suas vivências.

A fala da participante 3, Maria de Lourdes, nos é particularmente interessante. Ela tinha 96 anos no momento da enunciação e começou a frequentar a UnATI aos 81, quando estava doente e seu médico recomendou que ela frequentasse o projeto. A partir das projeções metonímicas: "A UnATI foi o melhor remédio que ela tomou", "A UnATI é o melhor remédio para os idosos", "A UnATI cura doenças e substitui médicos especialistas", assim como em todos os depoimentos e falas recortadas do corpus, emergem informações institucionais sobre a UnATI. Portanto, acredita-se que seja possível através dessa rede lexical presente nas falas dos alunos, construir um $\mathrm{MCl}$ da própria UnATI como instituição. Tal $\mathrm{MCl}$ foi incluído neste trabalho no final da seção dedicada à análise.

Hélio (participante 4 - Quadro 2), não discute seu passado antes da UnATI, focalizando as experiências positivas com o projeto: “O melhor é a convivência, se 
relacionar com pessoas da mesma idade, fazer novas amizades". Contudo, sua identidade discursiva nos remete a construção de um esquema imagético, baseado a priori no fato de que o passado seria uma oposição do presente. Como uma hipótese de que, se agora ele tem facilidade de fazer amizades e convive melhor com as pessoas, conclui-se que socialmente que, sua experiência não era assim no passado, ou seja, antes de frequentar os cursos e oficinas da UnATI.

Outro aspecto que apresenta relevância neste estudo é a revelação de como essas pessoas chegam até a UnATI. Para ilustrar este percurso, lançamos mão de esquemasimagéticos. Eles são domínios mentais apriorísticos criados a partir de experiências corporais e linguísticas e também do contexto (LAKOFF, 1987). Em outras palavras, é como se houvesse uma ponte entre as experiências do corpo e as estruturas cognitivas, neste caso, a linguagem. As colocações lexicais que refletem essa trajetória podem ser vistas no esquema abaixo (Figura 1).

Figura 1- Esquema Imagético

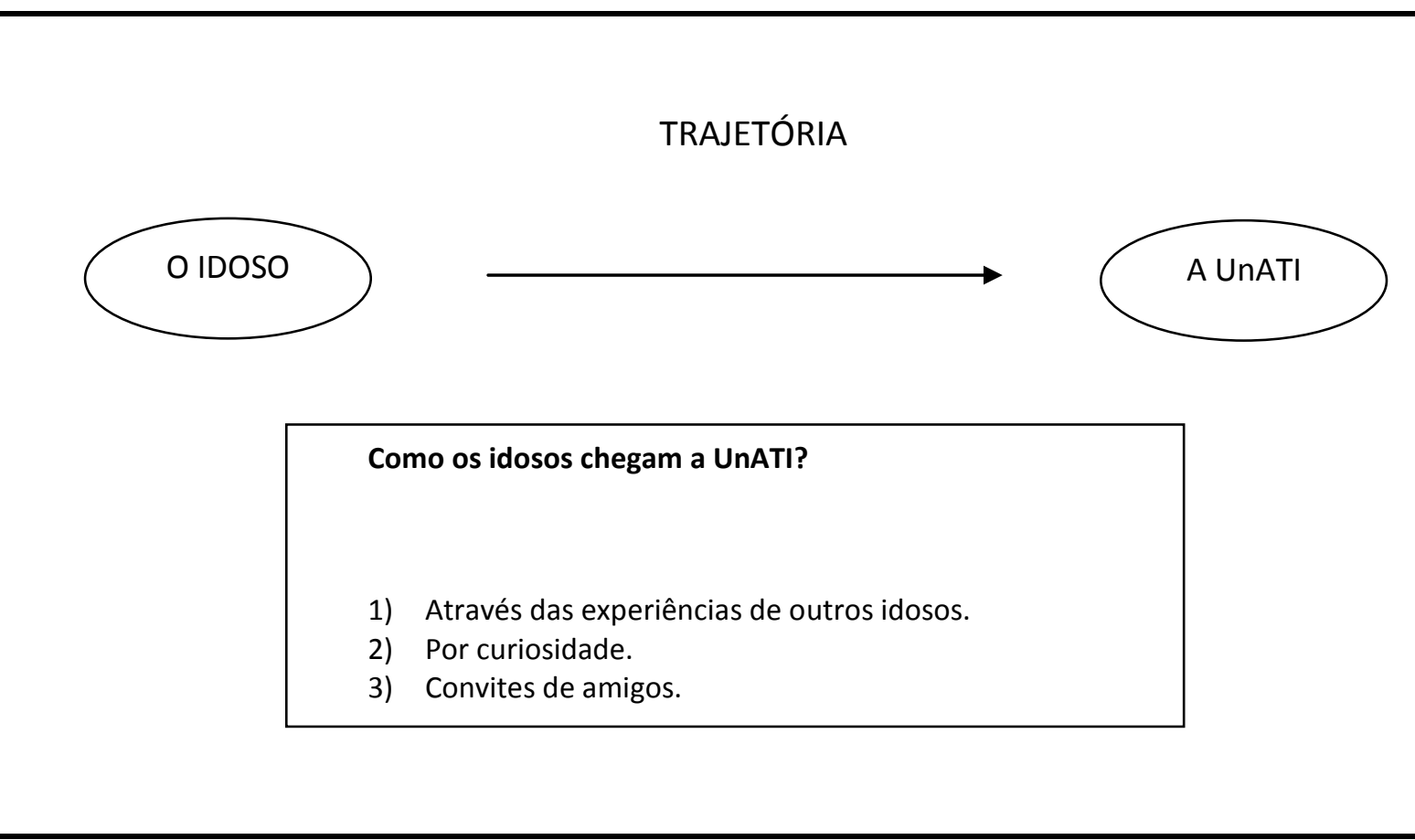


1) "Ele conta que ouviu falar sobre os cursos e resolveu ir até lá saber como funcionava e acabou ficando."

2) "Aí eu converso: vamos fazer um curso de biodança, de xadrez."

3) "Chegou levada pelo então vice coordenador, Dr. Paulo Henrique."

4) “Comecei a frequentar a UnATI após a viuvez, há uns oito, nove anos. Estava chegando quase à depressão e um médico amigo me sugeriu que viesse."

O esquema da Figura 1 reflete as experiências dos idosos quando se movimentam e se relacionam com outros idosos e outras pessoas em geral. Há forças interacionais agindo na construção do sentido que funcionam como mais um espaço de significação. De uma forma geral, o esquema acima resume o ponto de partida e ponto de chegada. No caso, o ponto de partida seriam as necessidades relativas ao envelhecimento, como problemas de saúde e uma escassez de relações interpessoais. Os aspectos negativos relatados no $\mathrm{MCl} 1$ (Quadro 1 ) impulsionam o idoso a começar a trajetória até a UnATI. Entretanto, a jornada só começa com as características descritas nos quatro itens que aparecem no esquema (Figura 1): o relato ouvido a respeito das experiências de outros idosos, a curiosidade aguçada pelos relatos, o convite daqueles que já participam e a recomendação médica. O ponto de chegada é apresentado como a solução. Ademais, a UnATI surge também como o ponto de transformação, onde as características negativas do $\mathrm{MCl} 1$ são abandonadas. Outro exemplo dessa transformação surge no depoimento 5 (Quadro 2): "Quando eu estou aqui, sou outra pessoa", com "outra" carregando conotação positiva.

Por fim, as referências linguísticas (em negrito, depoimento 5 - Quadro 2) que constroem a identidade da aluna Abiesilda nos fazem inferir que ela é influente no contexto da UnATI, já que consegue frequentar aulas mesmo quando não há vagas nas 
turmas. Dessa forma, há uma sugestão de que se trata de uma aluna popular entre professores e colegas. Percebemos, ainda, que é uma pessoa que teve oportunidades de estudar quando jovem, já que frequentava aulas de francês.

\section{$5.2 \mathrm{OMCl}$ dos Idosos da UnATI}

Após a ativação do $\mathrm{MCl}$ dos idosos pela sociedade (Quadro 1) e a construção do $\mathrm{MCl}$ dos Idosos pelos Idosos (Quadro 2), seguidas pelas análises das colocações lexicais em cada um desses MCls, almejamos agora conjugar as análises, cristalizando os pontos semelhantes e os pontos contrastantes, com a intenção de construir um $\mathrm{MCl}$ desse grupo de idosos que seja representativo dos idosos da UnATI. O Quadro 3 apresenta a conjunção das ativações desveladas no Quadro 1 e no Quadro 2, buscando construir as identidades variadas dos idosos da UnATI.

\section{Quadro 3 - Os idosos da UnATI}

- Faz cursos / oficinas: biodança, espanhol, música, teatro, cinema, psicomotricidade, produção de programas, dança de salão, francês

- Modelo da terceira idade

- Aluna antiga

- Bem de saúde, de paz, de amor

- Amigos, feliz, novas amizades

- Aposentado

- Convivência com outros idosos, relacionar com pessoas, namorada, esposa

- Mudança radical, casaram, namorar, representante

- Sorriu, esquecer "-istas", riso e alegria

- Esquecer doenças, e não sentir solidão

- Melhores recordações 
Pensando no $\mathrm{MCl}$ do Idoso da UnATI como um conjunto de conhecimentos estruturados no discurso dos idosos, com as construções cognitivas que puderam ser levantadas a partir da dinâmica desse discurso, analisamos as redes lexicais buscando semelhanças e diferenças, na tentativa de construir um $\mathrm{MCl}$ conclusivo a respeito das variadas identidades dos idosos que frequentam a UnATI.

Analisando o $\mathrm{MCl} 1$ (Quadro 1), pode-se dizer que ele é organizado em categorias, ou seja, podemos notar a presença de atributos que ativam esse $\mathrm{MCl}$, como as categorias negativas comummente associadas ao idoso (inútil, doente, imprestável, etc.). O MCl 1 é um exemplo típico de como os $\mathrm{MCls}$ podem nos ajudar e influenciar no que tange a organização dos nossos pensamentos, uma vez que corroboram a organização e a expressão das nossas expectativas como pessoas, visto que se ainda não somos, seremos um dia pessoas idosas.

Podemos considerar o $\mathrm{MCl} 1$ (Quadro 1) como uma representação do universo do idoso, explicitado como uma expectativa fortemente estruturada nos conhecimentos prévios a respeito da figura idosa, tanto que, as expectativas mais genéricas poderiam ser estruturadas também a partir de esquemas conceptuais que evocassem o papel do idoso em toda sociedade brasileira, em outras sociedades e assim por diante. Em algumas sociedades, o idoso é visto como um símbolo de experiência e sabedoria. Contudo, essas não são as referências lexicais que aparecem no $\mathrm{MCl}$ construído nesta pesquisa, onde idosos são retratados de forma majoritariamente negativa. Em outras palavras, de acordo com $\circ \mathrm{MCl} 1$, as colocações lexicais giram em torno dos aspectos negativos do envelhecimento e da figura do idoso. Isso é verificável também em outro domínio, o $\mathrm{MCl}$ 2 (Quadro 2, coluna 2), que representa o idoso antes de frequentar a UnATI. A postura negativa em relação ao idoso gera uma rejeição em relação ao processo de 
envelhecimento e ao idoso, sugerindo que eles deveriam ficar à margem do processo de construção da identidade pessoal e sociocultural. Essa imagem é materializada quando o idoso fala de si mesmo antes de frequentar a UnATI, descrevendo-se como uma pessoa doente, triste, sem vida e incapaz, como vemos no $\mathrm{MCl} 1$ (Quadro 1).

A ligação sistêmica que aparece no quadro abaixo entre os domínios: o idoso pela sociedade, o idoso pelo idoso antes da UnATI, o idoso pelo idoso depois da UnATI e o idoso da UnATI projetam identidades positivas em relação ao grupo revelado: as identidades dos idosos da UnATI.

A UnATI seria então, a instância capaz de auxiliar e promover transformação e mudança na vida do idoso, sendo esse empoderamento uma das chaves para tornar o idoso um membro ativo da sociedade, apagando, ou pelo menos reduzindo o estigma negativo verificado na projeção inicial. As oficinas, os cursos, assim como a convivência com outros idosos seriam então, formas de a UnATI atuar como o elemento responsável pela transformação das identidades negativas dos idosos em identidades positivas. Como exemplo, observe a projeção que segue:

Figura 2 - Projeção entre os domínios: MC1 e MC2

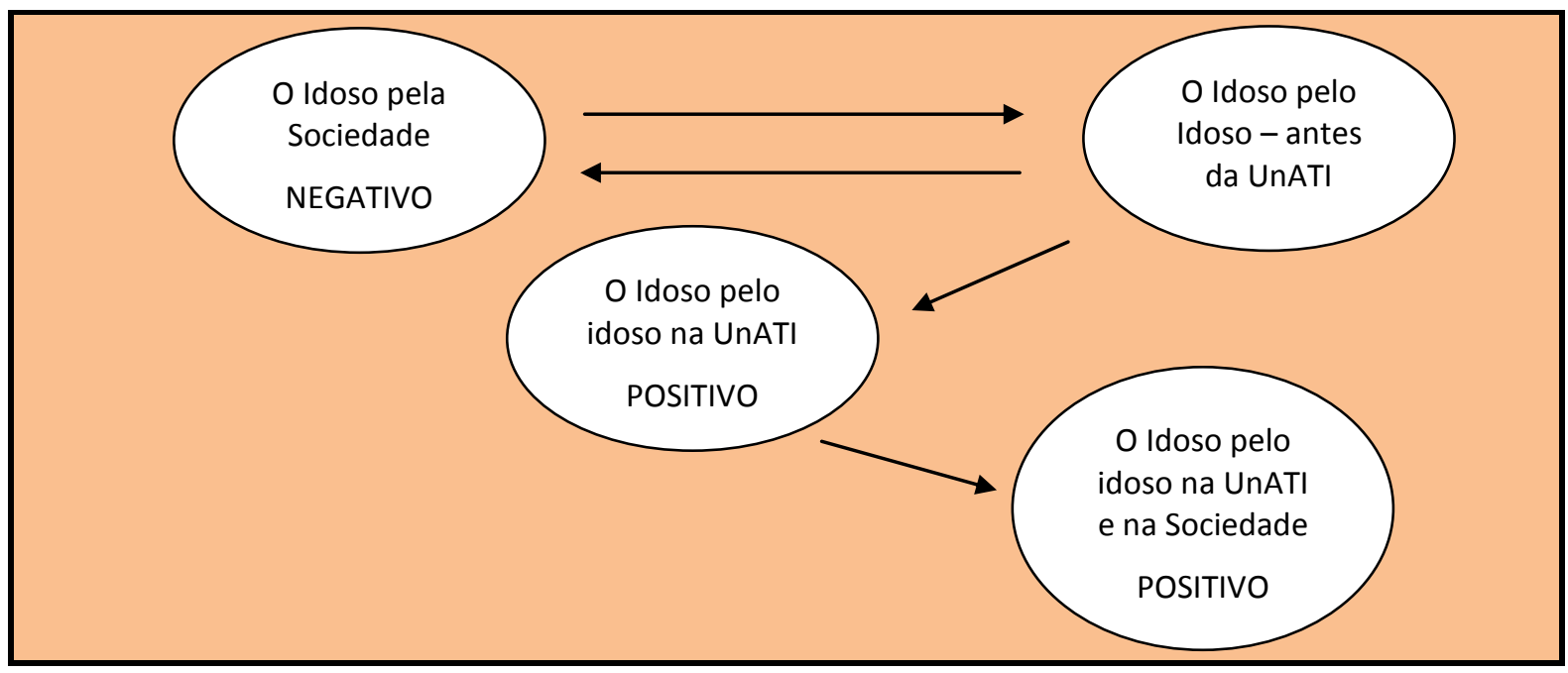


No esquema acima (Figura 2), a UnATI é projetada como um filtro transformador. Por isso, retomamos o domínio mencionado anteriormente sobre a UnATI com uma instituição. A identidade institucional desse filtro é capaz de transformar o comportamento e as identidades sociais. Retomamos essa projeção como base em uma das quatro características que todo $\mathrm{MCl}$ possui. Neste caso, o mais adequado seria a projeção metonímica, nas palavras do depoimento do médico publicado no corpus de pesquisa: "A UnATI foi o melhor remédio que ela tomou", "A UnATI é o melhor remédio para os idosos", "A UnATI cura doenças e substitui médicos especialistas". A partir dessas projeções é possível perceber que várias informações institucionais sobre a UnATI começam a emergir para formar mais uma identidade. Desta vez, trata-se de uma identidade institucional, sendo possível por meio da rede lexical presente nas falas dos alunos, ativar e revelar um $\mathrm{MCl}$ da UnATI como instituição, como apontado no Quadro 4 a seguir.

Quadro 4-O MCl da UnATI

- Possui cursos e oficinas: biodança, espanhol, música, teatro, cinema, psicomotricidade, produção de programas, dança de salão, francês

- Trabalha o corpo, a emoção e a mente

- Tem histórias de pessoas que começaram a namorar aqui e se casaram

- Tem 15 primaveras

- Foi o melhor remédio que lhe receitou

- Faz a gente esquecer todos os 'istas'

- Aqui, sou outra pessoa

- Na UnATI, o melhor é a convivência

De acordo com as pistas lexicais relacionadas no $\mathrm{MCl}$ da UnATI (Quadro 4), a identidade institucional que emerge da rede lexical que representa a UnATI para os 
idosos vai muito além do contexto institucional de universidade, escola ou centro de estudos. Os traços metonímicos já citados corroboram essa imagem de "filtro transformador de atitudes" capaz de transformar uma imagem negativa em uma positiva

e de transformar uma pessoa estigmatizada pela sociedade em uma pessoa feliz e respeitada, integrante de um grupo social.

Por fim, podemos identificar o idoso da UnATI como um idoso feliz, com o projeto atuando como um gatilho, um impulso e um filtro que serve para referenciar a entidade alvo, o idoso, pois ele é o objeto alvo a ser "transformado". A UnATI seria então um tratamento eficaz, um remédio recomendado para essa etapa da vida.

\section{Considerações finais}

Acreditamos que o $\mathrm{MCl}$ dos idosos da UnATI projetados pelos depoimentos dos frequentadores das oficinas e cursos seja positivo. Isto é, os idosos da UnATI projetam-se em uma categoria de idosos felizes e positivos. Tal categoria acomoda tanto os idosos que frequentam a UnATI com a própria UnATI como instituição, pois é ela a responsável por tal transformação positiva que surge como reflexo na instituição e da instituição.

A partir da análise dos dados é possível responder as perguntas que orientaram este estudo. Quais são as identidades discursivas dos idosos projetadas pelos depoimentos, falas e citações publicadas no corpus analisado? Primeiramente, não há apenas uma identidade, mas várias. A primeira é a identidade projetada negativamente, aquela ainda anterior a UnATI e há também as identidades refletidas após o convívio e a interação com a UnATI, essas identidades são transformadas e ganham projeção positiva. 
Como os $\mathrm{MCls}$ podem ajudar na elaboração de objetivos, metas que possam nortear a criação de novas oficinas e cursos, tanto para os idosos quanto para aqueles que trabalham diretamente com eles? Todo o $\mathrm{MCl} 1$ (Figura 1) onde as identidades negativas dos idosos se projetam de forma forte e latente podem servir como base para a escolha de temas a serem trabalhados nas oficinas e nos cursos que já existem na UnATI. Podem também servir de tema para debates e assuntos a serem abordados durante as aulas pelos professores e profissionais que trabalham com os idosos. Vale ressaltar que, através da projeção dos MCls desta pesquisa, a UnATI, como instituição é de longe o tema que ainda merece muitos estudos e pesquisas, já que foi muito produtivo descobrir que o papel da UnATI em relação ao comportamento e a construção dessas múltiplas identidades dos idosos vai muito além de uma simples definição de instituição.

\section{Referências}

FAIRCLOUGH, N. Discourse and social change. London: Polity Press, 1992.

GOFFMAN, E. Footing. Em RIBEIRO, Branca Telles e GARCEZ, Pedro M (orgs.).

Sociolinguística Interacional: Antropologia, Linguística e Sociologia em análise do discurso (107-148), 1998.

GONÇALVES, A. K. Ser idoso no mundo: o indivíduo idoso e a vivência de atividades físicas como meio de afirmação e identidade social. São Paulo, $214 \mathrm{f}$. Tese (Doutorado em Psicologia) - Instituto de Psicologia, Universidade de São Paulo, 1999.

GONÇALVES, A. K. Idoso e Identidade Social - LABORE: Laboratório de Estudos Contemporâneos - Polêmica - Revista Eletrônica, 2008.

LAKOFF, G. Women, fire and dangerous things. Chicago: The University of Chicago Press, 1987. 
LOPES, Marcia Oliveira Maciel. Leitura: uma categoria híbrida - pistas do discurso dos professores da rede particular e pública. Dissertação (Mestrado em Estudos da Linguagem) - Pontifícia Universidade Católica do Rio de Janeiro, 2006.

MARCHUSCHI, L. A. Análise da conversação. São Paulo: Ática, 2001. (série princípios). MOITA LOPES, L. P. Socioconstrucionismo: discurso e identidades sociais. In: MOITA LOPES, L. P. (org.). Discurso de identidades. São Paulo: Mercado das Letras, 2003.

PRADO, S.D.; SAYD J. D. A pesquisa sobre envelhecimento humano no Brasil: grupos e linhas de pesquisa. Ciência \& Saúde Coletiva; 9(1): 57-67, 2004.

ROGERS, R. A critical discourse analysis of literate identities across contexts: alignment and conflict. In: ROGERS, R. A Critical Discourse Analysis in education (51-79). New Jersey: Lawrence Erlbaum, 2004.

SALOMÃO, Maria Margarida Martins. A questão da construção do sentido e a revisão da agenda dos estudos da linguagem. Veredas: Revista de Estudos Linguísticos. Juiz de Fora, v. $3-$ n. 1 - p. 61-79, 2006.

SCHIFFRIN, D. From linguistic reference to social reality. In Anna de Fina, Deborah Schiffrin and Michael Bamberg. Discourse and Identity. Cambridge: Cambridge University Press, 2006. p. 103-131.

SHERMAN, N. C.; GOLD, J. A. Perceptions of ideal and typical middle and old age. The International Journal of Aging \& Development, n. 1, v. 9, p. 67-73, 1978/1979.

SOUSA, Karla Cecília Delgado Nunes. Construindo a identidade do idoso: de ator político a sujeito de direitos especial ou identificado, Recife, Anais Conpedi, 2008.

VERAS, Renato; DUTRA, Sidney. PERFIL DO IDOSO BRASILEIRO: Questionário Boas. Rio de Janeiro: UnATI, UERJ. 98 p., 2008.

BRASIL. Estatudo do Idoso - Lei 10.741 de 1/10/2003 - Dispõe sobre o Estatuto do Idoso e dá outras providências. Autor da lei: Senador Paulo Paim PT/RS - Brasília, 2003.

OMS. Envelhecimento ativo: uma política de saúde / World Health Organization; Tradução Suzana Gontijo. - Brasília: Organização Pan-Americana da Saúde, 2005. 60p.: il. Título original inglês: Active ageing: a policy framework. WHO/NMH/NPH/02.8. 


\title{
Anexos
}

\begin{abstract}
Anexo 1:
Depoimento 1: "Fiz o curso de biodança, depois espanhol, música e a oficina de teatro. Faço cinema e psicomotricidade, que trabalha o corpo, a emoção e a mente. Agora mesmo, terminei um curso de produção em que preparamos um programa de TV. E ainda desfilo, sou modelo da terceira idade. Comecei a frequentar a UnATI após a viuvez, há uns oito, nove anos. Estava chegando quase à depressão e um médico amigo me sugeriu que viesse. Vou fazer 77 anos, estou bem de saúde, de paz e de amor. Tenho um filho maravilhoso, três netos maravilhosos e grandes amigos. Sou uma pessoa feliz." (laracy Casaes, aluna da UnATI,)
\end{abstract}

\section{Anexo 2:}

Depoimento 2: "Tem idosas que perdem o marido e chegam aqui de cabecinha baixa, não querem fazer as atividades. Aí eu converso: vamos fazer um curso de biodança, de xadrez!

E ela vem. Nas primeiras semanas, com uma carinha feia. Na quarta semana ou na quinta, já é uma mudança radical. Tem histórias de pessoas que começaram a namorar aqui e se casaram." (Angélica Conte, representante dos alunos da UnATI)

\section{Anexo 3:}

Depoimento 3: Maria de Lourdes Salles, 96 anos e aluna da UnATI desde o dia de sua fundação. Ela acompanhou cada uma dessas 15 primaveras, frequentou um sem-número de cursos e oficinas, fez amigos, sorriu muito e guarda desse convívio as melhores recordações. Chegou levada pelo então vice-coordenador, Dr. Paulo Henrique, que era também seu médico. E esse, garante, foi o melhor remédio que lhe receitou. "Ele não sabia que, naquele momento,

\section{Anexo 4:}

Depoimento 4: Maria de Lourdes Salles, 96 anos e aluna da UnATI desde o dia de sua fundação. Ela acompanhou cada uma dessas 15 primaveras, frequentou um sem-número de cursos e oficinas, fez amigos, sorriu muito e guarda desse convívio as melhores recordações. Chegou levada pelo então vice-coordenador, Dr. Paulo Henrique, que era também seu médico. E esse, garante, foi o melhor remédio que lhe receitou. "Ele não sabia que, naquele momento, estava receitando o remédio mais eficaz que um idoso pode conseguir. Costumo dizer que a Unati faz a gente esquecer todos os 'istas': 
ortopedistas, alergistas, cardiologistas... A gente esquece a doença, é só riso e alegria, não há motivo pra tristeza. Tem a força de olhar para o rosto dos outros e não sentir solidão".

Anexo 5:

Depoimento 5: Hélio Casimiro da Silva, frequentador das aulas de dança de salão, é aposentado e participa do UnATI há 10 anos. Ele conta que ouviu falar sobre os cursos e resolveu ir até lá saber como funcionava e acabou ficando. "O melhor é a convivência, se relacionar com pessoas da mesma idade, fazer novas amizades", diz Hélio.

Anexo 6:

Depoimento 6: Quando eu estou aqui, sou outra pessoa" afirma. Abiesilda confessa que como é aluna antiga, os professores sempre dão um jeito pra que ela assista às aulas mesmo quando não têm mais vagas. Ela diz que ano que vem pretende se inscrever nas aulas de francês, pois estudou o idioma na escola, quando era jovem.

Recebido em 7 de agosto de 2018.

Aceite em 9 de dezembro de 2018. 